\title{
Radiotherapy of brain metastases from non-small cell lung cancer
}

\author{
Esra Korkmaz Kirakli', Ufuk Yilmaz ${ }^{2}$ \\ 'Department of Radiation Oncology, Dr. Suat Seren Chest Disease and Surgery Training and Research Hospital, İzmir 35200, \\ Turkey. \\ ${ }^{2}$ Department of Pulmonology, University of Health Science, Dr. Suat Seren Chest Disease and Surgery Training and Research \\ Hospital, İzmir 35200, Turkey.
}

Correspondence to: Dr. Esra Korkmaz Kirakli, Department of Radiation Oncology, University of Health Science, Dr. Suat Seren Chest Disease and Surgery Training and Research Hospital, İzmir 35200, Turkey. E-mail: esrakirakli@gmail.com

How to cite this article: Kirakli EK, Yilmaz U. Radiotherapy of brain metastases from non-small cell lung cancer. J Cancer Metastasis Treat 2019;5:10. http://dx.doi.org/10.20517/2394-4722.2018.73

Received: 13 Nov 2018 First Decision: 17 Dec 2018 Revised: 19 Dec 2018 Accepted: 22 Dec 2018 Published: 19 Feb 2019

Science Editor: Lucyna Kepka Copy Editor: Cui Yu Production Editor: Huan-Liang Wu

\begin{abstract}
Brain metastases risk at the time of diagnosis or during the course of disease is high in non-small cell lung cancer (NSCLC). Even the incidence of brain metastases has increased in recent years, due to detection of smaller asymptomatic lesions with MRI screening as well as improved survival as a consequence of developments in systemic therapies. In the last decade, there have been many trials in the management of NSCLC patients with brain metastases, questioning the role of adjuvant whole brain radiotherapy (WBRT) after surgery or stereotactic radiosurgery (SRS), WBRT, compared to best supportive care in patients not amenable to surgery, aggressive local therapies in solitary brain metastases, postsurgical cavity SRS, SRS in non-oligometastatic patients, cranial radiotherapy in patients with driver mutations, thyrosine kinase inhibitors, immune check point inhibitors and the impact of therapies on neurocognitive functions and quality of life. The main objective of this review is to provide an update on current trends in radiotherapy in the management of newly diagnosed brain metastases from NSCLC.
\end{abstract}

Keywords: Radiotherapy, whole-brain radiotherapy, stereotactic radiotherapy, stereotactic radiosurgery, brain metastases, lung cancer

\footnotetext{
(@) ( $)$

(C) The Author(s) 2019. Open Access This article is licensed under a Creative Commons Attribution 4.0 International License (https://creativecommons.org/licenses/by/4.0/), which permits unrestricted use, sharing, adaptation, distribution and reproduction in any medium or format, for any purpose, even commercially, as long as you give appropriate credit to the original author(s) and the source, provide a link to the Creative Commons license, and indicate if changes were made.
}

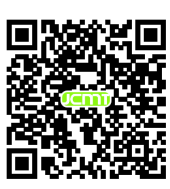




\section{INTRODUCTION}

Brain metastases are the most frequent malign brain tumors. Lung cancer is the leading primary tumor composing $40 \%-50 \%$ of cases $^{[1,2]}$. In non-small cell lung cancer (NSCLC) brain metastases risk at the time of diagnosis is $15 \%-20 \%$, even the risk increases to $50 \%-60 \%$ during their course of disease in patients with epidermal growth factor receptor (EGFR) mutation or anaplastic lymphoma kinase (ALK) rearrangement ${ }^{[3,4]}$.

Incidence of brain metastases has increased in recent years as a result of detection of smaller asymptomatic lesions with MRI screening as well as improved survival as a consequence of developments in systemic therapies. In addition to these, improvements in imaging technology, surgery, radiotherapy, targeted therapies, even immunotherapy and deep understanding of treatment related toxicities have resulted in evolvement of current trends in management of brain metastases ${ }^{[5,6]}$.

Althoughbrain metastases is an indicator of poor outcome $e^{[7,8]}$, it's shown that a subgroup might have longer survival, e.g., EGFR mutated and ALK rearranged NSCLC ${ }^{[4,9]}$. In this context, to assist the selection of personalized therapy several prognostic indices have been developed; e.g., recursive partitioning analysis, diagnosis-spesific graded prognostic assessment (DS-GPA) and more recently graded prognostic assessment for lung cancer using molecular markers (Lung-mol GPA) ${ }^{\left[10^{-12}\right]}$. Optimal treatment planning should consider both patient (age, performance status, expected life span) and tumor related factors (number and volume of brain metastases, extracranial disease control, molecular subtype).

Historically, whole brain radiotherapy (WBRT) or best supportive care were the only treatment modalities for patients with brain metastases. The aim of WBRT was to treat both microscopic and macroscopic metastases. But treatment to whole brain parenchyme reduces distant in-brain recurrences with the cost of $\operatorname{cognitive~toxicity~}^{[6]}$. In the last decade, there have been many trials in management of NSCLC patients with brain metastases, questioning the role of adjuvant WBRT after surgery or stereotactic radiosurgery (SRS), WBRT compared to best supportive care in patients not amenable to surgery, aggressive local therapies in solitary brain metastasis, postsurgical cavity SRS, SRS in non-oligometastatic patients, cranial radiotherapy in patients with driver mutations, TKI, immune check point inhibitors and the impact of therapies on neurocognitive functions (NCF) and quality of life (QOL).

The main objective of this review is to provide an update on current trends in radiotherapy in the management of newly diagnosed brain metastases from NSCLC.

\section{Solitary metastasis: WBRT vs. WBRT plus surgery}

Until Patchell et al. ${ }^{[13]}$ randomized trial of surgical resection followed by WBRT vs. WBRT only in patients with solitary brain metastasis, WBRT was the standard treatment. The findings of increased median suvival (10 months vs. 4-6 months), decreased brain recurrences (20\% vs. $52 \%$ ), increased functional independence and lower risk of neurological deaths with surgery in conjunction to WBRT, lead to increased role of aggressive local therapies in selected patients with solitary and oligo brain metastases ${ }^{[14-17]}$.

\section{Solitary metastasis: adjuvant WBRT plus surgery vs. surgery only}

The success of aggressive local treatment and fear of long-term neurologic toxicity led the authors to question the role of adjuvant WBRT in oligometastatic patients. Patchell et al ${ }^{[18]}$ randomized the patients with solitary brain matastasis after surgery to WBRT or observation. Postoperative WBRT reduced both local and distant brain failure rates significantly compared to observation arm (10\% vs. $46 \%, P<0.001),(14 \% v s .37 \%, P<0.01)$, respectively. Neurologic death rate was 3 times higher in the observation arm. But overall survival (OS) and survival with functional independence were the same ${ }^{[18]}$. 


\section{Solitary metastases: surgery vs. SRS}

In the absence of head to head randomized data, most of the retrospective studies comparing surgery $v s$. SRS reported similar outcomes in brain control or survival in solitary resectable brain metastases ${ }^{[1,20]}$. It's hard to make a decision when there is no indication for surgical decompression or need for histologic diagnosis. One small randomized study with 64 patients with solitary metastases, compared SRS to microsurgery plus WBRT. OS and 1 year local control were similar ${ }^{[21]}$. Recently, in secondary analysis of EORTC 22952 trial in abstract form which randomized patients to SRS or surgery with or without adjuvant WBRT, it was reported that early control was better with SRS but late control favored surgery ${ }^{[22]}$.

\section{Solitary metastasis: only SRS after surgery}

\section{Postoperative SRS vs. WBRT after resection of brain metastases}

The absence of survival advantage and recognized neurotoxicity of adjuvant WBRT after surgery have led to postoperative SRS to surgical cavity ${ }^{[6]}$. But there has been some challenges in the use of SRS without WBRT after surgical resection. First, the use has increased in trend although the data have been mainly derived from retrospective series ${ }^{[23,24]}$ and one prospective phase II trial ${ }^{[25]}$. The results of these studies report around $80 \%$ local control in 1 year suggest similar control rates with adjuvant WBRT. The only randomised data on this subject has been available from Kepka's multicenter trial, which did not demonstrate the noninferiority of postsurgical SRS compared to postsurgical WBRT in patients with solitary brain metastasis. The difference in neurocognitive failure at 6 months (primary end-point) was in favour of WBRT. Besides, although it was not the primary end-point; the patients in postsurgical SRS arm compared to postsurgical WBRT were found to have increased neurological deaths (66\% vs. 31\%, $P=0.015, \mathrm{HR}: 2.51)$ and decreased 2 years overall survival ( $10 \%$ vs. $37 \%, P=0.046$, HR: 1.8$)$, respectively ${ }^{[26]}$. The second challenge is that there have been some reports on dural-based leptomeningeal recurrences along the surgical tract after postoperative SRS ${ }^{[27,28]}$. Atalar et al. ${ }^{[27]}$ reported 13\% leptomeningeal recurrence rate at a median of 5 months after SRS directed to postsurgical resection cavity. It's hard to define target volume for postoperative SRS. Tumor cell dissemination along the surgical tract is another challenge. Recently, Soliman et al. ${ }^{[29]}$ reported a consensus guideline on delineation of CTV for postsurgical cavity SRS.

\section{Preoperative SRS}

In the context of leptomeningeal recurrences after postoperative SRS, preoperative SRS followed by surgical resection in $48 \mathrm{~h}$ is evolving as a new paradigm. The theoretical benefits are decreased radionecrosis and decreased leptomeningeal recurrences as a result of better definition of target volume by delineation of intact metastasis, a smaller margin volume and sterilization of surgical bed ${ }^{[6,30]}$. The results of preoperative SRS in 47 oligometastatic (1-3 brain metastases) patients before surgical resection have been reported by Asher et al. ${ }^{[5]}$ NSCLC patients were $37.2 \%$ of the cohort. The median dose was 14 Gy. The expansion margin of gross target volüme to planned target volüme was not used. There wasn't any difficulty during surgery or increased postoperative complication. In spite of the inclusion of relatively large lesions (median dimension $3.04 \mathrm{~cm}$ and median volume $8.49 \mathrm{~cm}^{3}$ ), local control rates were $97.8 \%, 85.6 \%$ and $71.8 \%$ at 6,12 and 24 months, respectively. Six of the 8 local relapsing patients were the ones who had either significant dural attachement or adherence to dural veins which might make an implication on the need for higher doses in such cases instead of dose reduction. There wasn't any leptomeningeal failure which confirms the hypothesis of the study. The authors concluded that preoperative SRS might be a better treatment at least for "high risk" patients $^{[5]}$. A phase II trial is going on this subject ${ }^{[31]}$.

\section{Oligometastases: WBRT alone vs. WBRT plus SRS boost}

In line with the intensification of local therapy Radiation Therapy Oncology Group (RTOG) conducted a phase 3 trial (RTOG 9508) which randomized 331 patients with 1-3 brain metastases to WBRT vs. WBRT plus SRS. Lung cancer patients were $64 \%$ of the patient cohort. SRS boost in conjunction to WBRT showed survival benefit in patients with 1 metastatic lesion (6.4 months $v s .4 .9$ months, $P=0.0393$ ). The addition of 
SRS resulted in increased local control in all patients $(82 \% v s .71 \%, P=0.01)$. There were improvement in survival, local control, performance status and decreased steroid dependence in NSCLC patients with 1-3 in post hoc analysis ${ }^{[17]}$. In the secondary analysis, the patients were re-statified according to GPA scoring system. There were 211 lung cancer patients out of 252 (84\%) re-analysed patients. It was found that SRS boost after WBRT resulted in increased survival in patients with GPA 3.5-4.0 score (good prognosis); the median survival was 21 months in WBRT + SRS vs. 10.3 monhs in WBRT only. The benefit was irrespective of the number of metastases ${ }^{[32]}$.

\section{Oligometastases: omitting adjuvant WBRT after surgery or SRS}

The indication of adjuvant WBRT after surgery or SRS has been evolving. The rationale of omitting immediate WBRT after surgery or SRS with close follow-up lies on the availibility to treat in-brain recurrences with salvage focal therapies or WBRT at relapse with the aim of avoiding neurocognitive dysfunction. To meet this challenge four phase 4 randomised trials and a metaanalysis was carried out ${ }^{[33-37]}$.

In this concept, the first randomized trial came from Japan (JRSOG-99 trial). The primary end point was the survival difference between SRS and WBRT plus SRS, but at interim analysis it was realized that sample size would be unachiavable and accrual was terminated. Aoyama et al. ${ }^{[33]}$ reported same survival rates (8 months vs. 7.5 months, $P=0.42)$ and same neurologic death rates $(19 \%$ vs. $23 \%)$ in spite of higher local recurrences $(27 \%$ vs. $11 \%)$ and distant brain recurrences $(64 \%$ vs. $41 \%)$ in 132 patients with 1 to 4 brain metastases treated with SRS alone vs. WBRT plus SRS. The authors claim that SRS alone might be a viable approach if the patient is compatible with close brain monitoring for the early detection of recurrence to have the ability for early salvage ${ }^{[33]}$. In a secondary analysis, 88 NSCLC patients were poststratified by DS-GPA and survival was the primary end-point. Forty seven patients with favorable DS-GPA score (2.5-4.0) had better OS with the addition of WBRT (16.7 months $v$ s. 10.6 months, $P=0.04)^{[38]}$.

From MD Anderson, Chang et al. ${ }^{[34]}$ reported the second randomized trial: 58 patients with 1-3 brain metastases were randomized to SRS alone $v s$. SRS followed by WBRT. The primary end-point of the study was declin in neurocognitive function measured by Hopkins Verbal Learning Test-Revised at 4 months compared to baseline but was terminated early due to high probability (96\%) of inferior outcome in learning and memory at 4 months in SRS plus WBRT arm. Local and distant in-brain controls were higher in SRS plus WBRT arm compared to SRS only ( $100 \%$ vs. $67 \%$ and $73 \%$ vs. $45 \%$, respectively). An addition of WBRT resulted in less need for salvage therapies $(11 \%$ vs. $90 \%$ ) but higher risk for neurological deaths in SRS plus WBRT group. (HR: 2.1, 95\% CI 0.8-6.0, $P=0.15$ ) and median survival was higher in SRS only group (15.2 months $v s$. 5.7 months). Higher survival in SRS only group was explained by higher rate of local surgical salvage and ability of the patients to have systemic chemotherapy 1 month earlier and median 2 more cycles ${ }^{[34]}$.

EORTC 22952 phase III randomized trial was the third with the largest patient number, unique in enrolling both SRS and surgicaly resected patients. Besides, in contrast to other two studies, it included only patients with systemic disease under control. The design was more complex; randomizing adjuvant WBRT $v s$. observation after surgery or SRS in systemically controlled 359 patients with 1-3 brain metastases. The primary end-point was survival time with functional independence. The local (surgery: $27 \% v s .59 \%, P<0.001$; SRS: $19 \%$ vs. $31 \%, P=0.04$ ) and distant brain recurrences (surgery: $23 \%$ vs. $42 \%, P<0.008$; SRS: $33 \%$ vs. $48 \%, P$ $=0.023)$, need for salvage therapy $(16 \% v s .51 \%)$ and neurological death rates because intracranial progression $(28 \% v s .44 \%)$ were decreased with addition of WBRT after surgery or SRS compared to observation but without difference in median duration of functional independence ( 9.5 months $v s .10$ months, $P=0.71$ ) and survival (10.9 months vs. 10.7 months, $P=0.89)^{[35]}$. In secondary analysis of EORTC 175 NSCLC patients were re-analyzed to evaluate the benefit of WBRT on survival of patients with favorable prognosis (high GPA); there wasn't any significant survival difference between patients with high or low GPA scores ${ }^{[39]}$. 
As seen from these three randomized controlled trials, intracranial control (both local and distant sites) was almost equal in both SRS and SRS plus WBRT groups but survival outcomes were conflicting though none of these trials were intended to address survival as the primary endpoint; both JRSOG and EORTC trials reported same survival rates with both treatment approaches, wheras MD Anderson trial reported higher survival in SRS only group. An individual patient data metaanalysis considering JRSOG, MD Anderson trials and only 199 patients treated with SRS plus or minus WBRT in EORTC was perfomed by Sahgal et al. ${ }^{[40]}$ It was reported that, in patients with single brain metastasis, overall survival was higher and distant in-brain recurrence was lower compared to the patients with 2-4 metastases. SRS alone resulted in survival advantage in patients $\leq 50$ years of age compared to their age-matched control treated with SRS plus WBRT without increase in distant brain recurrences. But there was no significantly higher neurological death in patients $\leq$ 50 years treated with SRS only ( $39 \%$ vs. $22 \%$ ). In patients $>50$ years of age distant in-brain recurrence risk was significantly higher in SRS only group but this increased recurrence did not translate to any survival disadvantage. When the data was re-evaluated considering only NSCLC patients the results were similar. But the authors emphasize that firm conclusion concerning histology could not be done because of limited sample size and reflection of subset analysis. As a conclusion, the authors suggest that SRS might be the treatment of choice in patients $\leq 50$ years with 1-4 metastases ${ }^{[40]}$.

Recently, Brown et al. ${ }^{[37]}$ have reported the effects of adjuvant WBRT on cognitive function in a randomized phase III (No574-Alliance) trial in patients with 1-3 metastases. The primary end-point was the amount of neurocognitive decline at 3 months compared to baseline. The local control was increased at 1 year with addition of WBRT to SRS ( $85 \%$ vs. 51\%). There wasn't any difference in terms of survival (10.1 months vs. 7.5 months $)^{[37]}$. Recently secondary analysis of N0574-Alliance has been reported in 126 NSCLC patients to determine if WBRT might be associated with prolonged survival in NSCLC patients with good performance status. The patients were scored according to DS-GPA scores. There was no significant differences in OS between SRS only or WBRT plus SRS groups in NSCLC patients with favorable DS-GPA scores. This study further supports the approach of SRS alone in the majority of patients with limited brain metastases ${ }^{[41]}$.

Neurocognitive impairement following WBRT after surgery or SRS vs. observation after surgery or SRS

The impact of adjuvant WBRT on NCF have been utilized in these previously mentioned 4 studies by different methods. JRSOG trial evaluated the Mini Mental State Examination (MMSE) results in SRS only and SRS plus adjuvant WBRT groups in long term. They revealed that the control of metastases increased the MMSE scores in 2-3 months after radiotherapy in both groups and but in late-term (36 months) deterioration of NCF in WBRT group was prominent. In the post hoc analysis, average time to neurocognitive decline was shorter in SRS only group compared to SRS plus WBRT group 7.6 months vs. 16.5 months, respectively. The authors claim that distant in-brain recurrence might have a bigger negative effect on neurocognition and control of metastases is the most important factor in stabilizing cognitive fuction ${ }^{[42]}$. But it should be mentioned that MMSE has been accepted as having lower sensitivity in detection of NCF changes ${ }^{[43]}$. Besides, the paucity of the data on neurocognition in this study prevents us from making a conclusion on the effect of WBRT on $\mathrm{NCF}^{[34]}$.

MD Anderson trial reported significant decrease in recall memory and learning at 4 months after WBRT plus SRS compared to SRS alone patients (52\% vs. 24\%) despite the decreased local and in-brain recurrences as described previously. The authors claimed that adverse effects of WBRT on neurogenesis in hippocampus might have a greater effect on neurocognition than in-brain recurrences and related salvage therapies seen more often in SRS only group ${ }^{[34]}$.

QOL analysis of EORTC 22952 trial declared a significant neurocognitive decline at 12 months and lower QOL scores in WBRT arm after surgery or SRS ${ }^{[4]}$. 
Table 1. Summary of randomised trials comparing stereotactic radiosurgery to stereotactic radiosurgery plus whole brain radiotherapy

\begin{tabular}{|c|c|c|c|c|c|c|c|c|c|c|c|c|c|}
\hline \multirow{3}{*}{$\begin{array}{l}\text { Study } \\
\text { JRSOG-99, } \\
\text { Aoyamaetal. }{ }^{[33]} \\
2006\end{array}$} & \multirow{3}{*}{$\begin{array}{c}\text { Patient } \\
\text { number } \\
132 \\
\end{array}$} & \multirow{3}{*}{$\begin{array}{c}\begin{array}{c}\text { Lung } \\
\text { cancer } \\
\text { patients } \\
\text { (\%) }\end{array} \\
66\end{array}$} & \multirow{3}{*}{$\begin{array}{c}\text { \# of brain } \\
\text { metastases }\end{array}$} & \multirow{3}{*}{$\begin{array}{l}\text { Type of test } \\
\text { MMSE }\end{array}$} & \multirow{2}{*}{\multicolumn{2}{|c|}{$\begin{array}{c}\text { Local } \\
\text { relaps (\%) } \\
\text { SRS SRS + } \\
\text { WBRT }\end{array}$}} & \multirow{2}{*}{\multicolumn{2}{|c|}{$\begin{array}{c}\begin{array}{c}\text { Distant } \\
\text { relaps } \\
(\%)\end{array} \\
\text { SRS SRS } \\
+ \text { WBRT } \\
\end{array}$}} & \multirow{2}{*}{\multicolumn{2}{|c|}{$\begin{array}{c}\text { Median OS } \\
\text { (month) } \\
\begin{array}{c}\text { SRS SRS + } \\
\text { WBRT }\end{array} \\
\end{array}$}} & \multirow{2}{*}{\multicolumn{2}{|c|}{$\begin{array}{c}\begin{array}{c}\text { Neurologic } \\
\text { death }(\%)\end{array} \\
\begin{array}{c}\text { SRS SRS + } \\
\text { WBRT }\end{array} \\
\end{array}$}} & \multirow{2}{*}{$\begin{array}{c}\text { Decline in NCF/QOL } \\
\text { SRS SRS + WBRT }\end{array}$} \\
\hline & & & & & & & & & & & & & \\
\hline & & & & & 27 & 11 & 64 & 41 & 8 & 7.5 & 19 & 23 & $\begin{array}{l}\text { Deterioration is earlier } \\
\text { in } \\
\text { SRS only gorup } \\
\text { at } 7.6 \text { month at } 16.5 \\
\text { month }\end{array}$ \\
\hline $\begin{array}{l}\text { MD Anderson, } \\
\text { Chang et al. }{ }^{[34]} \\
2009\end{array}$ & 58 & 67 & $1-3$ & HVLT-R & 33 & 0 & 55 & 27 & 15.2 & 5.7 & $\begin{array}{l}\text { SRS } \\
\text { risk } \\
\text { HR: } \\
\mathrm{ClO}\end{array}$ & $\begin{array}{l}\text { VBRT } \\
\text { death } \\
95 \% \\
.0\end{array}$ & $24 \% \quad 52 \%$ \\
\hline $\begin{array}{l}\text { EORTC22952, } \\
\text { Kocher et al. } \\
2011\end{array}$ & 359 & 53 & $1-3$ & $\begin{array}{l}\text { EORTC QLQ } \\
\text { C-30 } \\
\text { QLQ BN-20 }\end{array}$ & 31 & 19 & 48 & 33 & 10.7 & 10.9 & 44 & 28 & $\begin{array}{l}\text { Global health at } 9 \\
\text { month. } \\
63 \quad 52 \\
\text { Physical function at } 8 \\
\text { weeks } \\
52 \quad 42 \\
\text { Role fxn at } 8 \text { weeks } \\
64 \quad 58 \\
\text { Cognitive function at } \\
8 \text { weeks } \\
81 \quad 74 \\
\text { Cognitive function at } \\
12 \text { months } \\
80 \quad 69\end{array}$ \\
\hline $\begin{array}{l}\text { Alliance } \\
\text { N0574, } \\
\text { Brown et al. }{ }^{[37]} \\
2016\end{array}$ & 213 & 68 & $1-3$ & $\begin{array}{l}\text { FACT-Brain } \\
\text { ADL Index } \\
\text { HVLT-R } \\
\text { GPT, COWAT } \\
\text { TMT-A and B }\end{array}$ & 27 & 10 & 30 & 8 & 10.4 & 7.4 & NA & & $\begin{array}{l}\text { NCF at } 3 \text { months } \\
64 \% \quad 92 \% P< \\
0.001 \\
\text { QOL change from } \\
\text { baseline } \\
-0.1 \quad-20 \quad P=0.001\end{array}$ \\
\hline
\end{tabular}

SRS: stereotactic radiosurgery; WBRT: whole brain radiotherapy; OS: overall survival; NCF: neurocognitive functions; QOL: quality of life;MMSE: Mini Mental State Examination; HVLT-R: Hopkins Verbal Learning Test-Revised; FACT: functional assessment of cancer therapy; ADL: activities of daily living; GPT: Grooved Pegboard Test; COWAT: Controlled Oral Word Association Test; TMT: Trail Making Test Part $\mathrm{A}$ and $\mathrm{B}$

Alliance trial evaluated the amount of decline in neurocognitive function at 3 months compared to baseline with 6 different cognitive tests. The WBRT and SRS group showed significant decline compared to SRS alone group ( $92 \%$ vs. $64 \%, P<0.001)$ at 3 months. Among long term survivors, cognitive decline rates in SRS only and SRS plus WBRT groups were $45 \%$ vs. $94 \%(P=0.007)$ in 3 months and $60 \%$ vs. $94 \%(P=0.04)$ in 12 months, respectively, despite the increased local control in 1 year with the addition of WBRT ( $85 \% v s$. $51 \%)$. In each cognitive test there was higher deteroiration in SRS plus WBRT group, reaching statistical significance for immediate memory ( $30 \%$ vs. $8 \%, P=0.004)$, delayed memory $(51 . \% v s .20 \%, P<0.001)$ and verbal memory (17\% vs. $2 \%, P=0.01)$, respectively ${ }^{[37]}$.

The summary of these four trials can be seen in Table 1. As a whole, adjuvant WBRT reduces distant inbrain recurrence approximately by $50 \%$ and increases local control approximately by $15 \%-30 \%$, without any survival benefit ${ }^{[6]}$. Of note, as mentioned before, none of these trials were powered to evaluate survival difference. One explanation for the lack of survival benefit for adjuvant WBRT is the uncontrolled extracranial disease which is the proximate cause of death. But even the largest EORTC trial that enrolled only patients with systemic disease under control to eliminate the competing risk of death from extracranial disease and to be able to detect the survival advantage of WBRT if any, did not find any difference. Secondary analyses of JROSG 99 showed survival benefits of WBRT among NSCLC patients with high DSGPA scores (good prognosis). But, secondary analyses of EORTC and Alliance trials failed to confirm this result. On the other hand, efficacy of local salvage therapies in SRS only arm might also be attibuted to the lack of survival benefit ${ }^{[6]}$. Taken together, in the absence of survival advantage and recognized neurotoxicity of WBRT the results of these 4 trials suggest that in single or 24 brain metastases, SRS alone might be the 
preferred strategy in amenable patients willing to have frequent brain surveillance with MRI.

Similarly, the American Society for Radiation Oncology (ASTRO) does not recommend routine adjuvant WBRT in oligometastatic brain metastases in it's choosing wisely initiative organisation ${ }^{[45]}$.

On the other hand there have been several opposers to this approach, because they claim that there should be a trade between the risk of neurocognitive dysfunction and the risk of in-brain recurrences which could adversely worsen cognitive function even more than WBRT that might not be reversed by salvage therapies ${ }^{[46,47]}$.

\section{Solitary or oligometastatic or non-oligometastatic: WBRT only}

Brain metastases from the primary tumors occur mainly by hematogenous route making the whole brain under the risk for micrometastatic disease. This concept has been the rationale of WBRT even in case of small solitary metastasis but recently has started to be questioned in the context of true oligometastatic brain disease ${ }^{[33]}$. In patients with life expectancy less than 3 months and/or poor performance status, short course WBRT or best supportive care with corticosteroids are reasonable options ${ }^{[48]}$.

A phase III non-inferiority Medical Research Council trial (QUARTZ), comparing best supportive care alone and best supportive care plus WBRT in NSCLC patients with brain metastases not amenable to surgery or SRS, reported similar survival and QOL. Solitary metastasis rate was 30\% but median number of metastatic lesions and distribution of patients among two treatment arms according to number of metastastic lesions were not available in the data ${ }^{[49]}$. But there has been some debates on this article; $38 \%$ of the cohort had poor performance, the median survival was only 8 weeks which was much inferior compared to previous data ${ }^{[7]}$. Besides, due to heterogenity of prognosis in patients with brain metastases with different primaries the results can not be generalized ${ }^{[6]}$.

\section{Hippocampus sparing WBRT}

WBRT related neurocognitive complications have led to the developement of new radiotherapy techniques; hippocampus sparing WBRT (HS-WBRT) is one of them. The rationale lies on that; new memory is composed by neural stem cells located in the subgranular zone of the hippocampus and there is a doseresponse-related risk of decline in NCF due to radiation dose received by the $\mathrm{HP}^{[50]}$. Until recently, there have been only 2 prospective data on this subject. The first one, single-armed phase II RTOG-0933 trial, reported no increased risk of recurrence with HS-WBRT and better preservation of cognitive function with this technique compared to historical controls ${ }^{[51]}$. The second data is from Oehlke et al ${ }^{[52]}$ the progression in the hippocampus avoiding area was $2(10 \%)$ of 20 in 40 weeks. But recently, the preliminary results of a randomized trial (NRG-CC01) composed of 518 randomized patients to memantine and HS-WBRT arm vs. memantine and WBRT arm have been presented in the last ASTRO meeting. HS-WBRT has prolonged time to neurocognitive failure, decrease in neurocognitive function at 6 months was 59.5\% vs. $68.2 \%$ (HR: $0.76, P$ $=0.03)$ favoring HS-WBRT without any difference in intracranial brain recurrences or overall survival $(P=$ 0.208 and $P=0.307$, respectively) ${ }^{[53]}$.

\section{Memantine and WBRT}

Memantine has been tested in prevention of cognitive dysfunction as a neuroprotective agent in a randomized placebo controlled trial (RTOG 0614) and shown to be effective in decreasing the rate and delaying the time to cognitive decline ${ }^{[54]}$. There is an ongoing randomized clinical trial comparing memantine and WBRT with or wihout HA-WBRT ${ }^{[55]}$.

\section{Non-oligometastatic: SRS without WBRT}

There have been growing data on SRS without WBRT in patients with more than 3 brain metastases although the maximum number of metastases appropriate for SRS has not been established, yet ${ }^{[49]}$. The 
Japanese Leksell Gamma Knife Society reported the results of a prospective observational multicenter phase 2 (JLGK0901) study in which survival outcomes and treatment related toxicity of SRS without WBRT in 1,194 patients with single, 2-4 and 5-10 brain metastases were evaluated. Patients with solitary brain metastasis had the longest survival (median 13.9 months, 95\% CI 12.0-15.6). In this non-inferiority study, overall survival, local failure, distant in-brain recurrences, neurological death and toxicity were found to be similar both in patients presenting with 2-4 and 5-10 metastases. There was not any survival difference in lung cancer patients with 2-4 or 5-10 metastases either ${ }^{[56]}$. An update of this study which was planned to see the radiation related complications and changes in NCF in long-term reported that toxicity and MMSE scores were similar among the three groups ${ }^{[57]}$. There have been two clinical trials recruiting patients with estimated study completion date of 2022. One of them led by National Cancer Information Center, is ramdomizing patients with 5-15 brain metastases to SRS or WBRT plus memantine. Overall and neurocognitive deterioration free survival are the primary endpoints ${ }^{[58]}$. The other one is from Dana-Farber Cancer Institute and ramdomizing patients with 5-20 brain metastases to SRS or WBRT plus hippocampal sparing in available cases, the QOL is the primary end-point ${ }^{[59]}$.

\section{SRS vs, fractionated SRS}

In the absence of randomized trial comparing SRS $v s$. fractionated SRS (FSRS); FSRS might be the option with lower risk of radionecrosis in large lesions ${ }^{[60]}$.

\section{TKI and radiotherapy}

NSCLC patients having driver mutations (EGFR mutation and ALK rearrangement) in NSCLC have increased risks of brain metastases both at the time of diagnosis and during the course of the disease ${ }^{[3,4]}$. TKI targeting EGFR and ALK pathways have resulted in encouraging intracranial control rates compared to chemotherapy $^{[61]}$.

\section{Witholding radiotherapy in asymptomatic patients with driver mutations}

Recently reported three phase II trials advocate witholding radiotherapy (SRS or WBRT) until progression if small asymptomatic brain metastases are present in an EGFR mutation positive NSCLC patient ${ }^{[62-64]}$. There are several explanations; first, targeted therapies have greater intracranial activity compared to historical chemotherapeutic agents. Secondly, prolongation of survival with these agents allows time for manifestation of neurocognitive side effects if radiotherapy is the treatment of choice ${ }^{[65]}$. But patients should have the willingness to close surveillance with MRI, though the optimal interval is unknown. Contrary to these trials, recently, a retrospective multiinstitutional analysis reported inferior survival with up-front EGFRTKI in EGFR mutant NSCLC patients with brain metastases, both up-front SRS and up-front WBRT were found to be associated with higher survival compared to up-front EGFR-TKI in multivariate analysis, (HR: 0.39, 95\% CI 0.26-0.58 and HR: 0.70, 95\% CI 0.50-0.98), respectively ${ }^{[66]}$. The debate will be going on until a randomized trial's results, comparing up-front radiotherapy followed by EGFR-TKI to up-front EGFR-TKI followed by radiotherapy at progression in EGFR mutated NSCLC patients.

A retrospective analysis of NSCLC patients with brain metastases and ALK rearrangement, showed prolonged time to intracranial progression with up-front cranial radiotherapy adjunct to first generation ALK inhibitor (crizitonib) compared to patients without cranial radiotherapy, (13.2 months vs. 7 months, respectively $)^{[67]}$. Second and third generation ALK inhibitors have better blood brain barrier penetration kinetics which might change the indications for cranial radiotherapy in the near future ${ }^{[61]}$. Updated ALEX trial comparing crizotinib $v s$. alectinib in stage IIIB/IV (asymptomatic brain metastases were allowed) reported median PFS 27.7 months with alectinib vs. 7.4 months with crizotinib (HR: 0.35, 95\% CI 0.220.56), cranial response rates were $59 \%$ vs. $26 \%$ and complete cranial response rates were $45 \%$ vs. $9 \%$ in patients presented with brain metastases at the time of diagnosis, respectively ${ }^{[68]}$. As a result of these striking results, postponing the cranial radiotherapy might be reasonable in ALK rearrangement positive patients if Alectinib was the treatment of choice in first line. 


\section{Sequencing of radiotherapy and TKI}

It's recommended to withold TKI during WBRT to decrease unexpected toxicity which was observed with concurrent use of erlotinib and WBRT ${ }^{[69]}$. If SRS were the treatment of choise, similarly witholding TKI and resuming one day after SRS is usually recommended in the absence of data.

\section{Immune checkpoint inhibitors and radiotherapy}

Although the prospective data is lacking, the data on immune checkpoint inhibitors targeting the programmed cell death 1 pathway (PD1) in NSCLC patients with brain metastases has been growing. In a phase II trial it was reported that pembrolizumab showed 33\% intracranial response rate ${ }^{[70]}$. But nivolumab led to discontinuation of treatment in $58 \%$ of patients, because of progression of neurologic symptoms which might be the reflection of pseudoprogression or hyperprogression ${ }^{[7]}$. A recent retrospective study reported higher OS in multivariate analysis that concurrent use of anti-PD1 and SRS resulted higher OS compared to sequential use $(P=0.006)$ or SRS alone $(P=0.002)$ or anti cytotoxic T-lymphocyte-associated protein $4(P=$ 0.045). Concurrent use also reduced distant intracranial relapses ${ }^{[72]}$.

\section{Sequencing of radiotherapy and immune checkpoint inhibitors}

Several retrospective data have reported no increased toxicity with the concurrent use of immunotherapy and cranial radiotherapy in NSCLC, though prospective studies are needed to confirm this finding ${ }^{[73]}$. There have been several clinical trials recruiting patients testing the efficacy of immunotherapy in combination with radiotherapy in NSCLC patients with brain metastases (NCT02978404, NCT02858869, NCT02696993)

\section{CONCLUSION}

Taken together, these trials suggest survival advantage of surgery or SRS in selected patients with sollitary metastasis but no survival advantage of certain treatment option in oligometastatic patients; they differ only in terms of local or distant in-brain control. Besides, QOL assesements have inconsistent results and has yet to be defined. Optimal treatment planning should consider both patient (age, performance status, expected life span) and tumor related factors (number and volume of brain metastases, extracranial disease control, molecular subtype) by using new prognostic models which is in line with personalised medicine and tailored therapy approach rather than "one size fits all”. In light of today's knowledge, it is quite likely that the trade would be going on between doctors and patients, considering QOL as an outcome of neurocognitive function that might be deteriorated either by symptomatic brain recurrence(s) or treatment related morbidity.

Surgical cavity directed SRS seems to be effective in local control and preservation of NCF compared to WBRT but the optimal sequencing (postopereative or preoperative) should be defined.

In non-oligometastatic patients the role of SRS has been evolving, the results of randomized studies might help in decision making.

Targeted therapy and immune checkpoint inhibitors have resulted in increased intracranial activity compared to chemotherapy, but the evidence is not strong enough to defer local therapy and the use as upfront therapy. Also, there are ongoing trials exploring the technique and the methods to spare the NCF.

\section{DECLARATIONS}

\section{Authors' contributions}

All authors contributed equally to the article.

\section{Availability of data and materials}

Not applicable. 


\section{Financial support and sponsorship}

None.

\section{Conflicts of interest}

All authors declared that there are no conflicts of interest.

\section{Ethical approval and consent to participate}

Not applicable.

\section{Consent for publication}

Not applicable.

\section{Copyright}

(C) The Author(s) 2019.

\section{REFERENCES}

1. Barnholtz-Sloan JS, Sloan AE, Davis FG, Vigneau FD, Lai P, et al. Incidence proportions of brain metastases in patients diagnosed (1973 to 2001) in the Metropolitan Detroit Cancer Surveillance System. J Clin Oncol 2004;22:2865-72.

2. Schouten LJ, Rutten J, Huveneers HA, Twijnstra A. Incidence of brain metastases in a cohort of patients with carcinoma of the breast, colon, kidney, and lung and melanoma. Cancer 2002;94:2698-705.

3. Zhang I, Zaorsky NG, Palmer JD, Mehra R, Lu B. Targeting brain metastases in ALK-rearranged non-small-cell lung cancer. Lancet Oncol 2015;16:e510-21.

4. Johung KL, Yeh N, Desai NB, Williams TM, Lautenschlaeger T, et al. Extended survival and prognostic factors for patients with ALKrearranged non-small-cell lung cancer and brain metastasis. J Clin Oncol 2016;34:123-9.

5. Asher AL, Burri SH, Wiggins WF, Kelly RP, Boltes MO, et al. A new treatment paradigm: neoadjuvant radiosurgery before surgical resection of brain metastases with analysis of local tumor recurrence. Int J Radiat Oncol Biol Phys 2014;88:899-906.

6. Churilla TM,Weiss SE. Emerging trends in the management of brain metastases from non-small cell lung cancer. Curr Oncol Rep 2018;20:54

7. Sperduto PW, Kased N, Roberge D, Xu Z, Shanley R, et al. Summary report on the graded prognostic assessment: an accurate and facile diagnosis-specific tool to estimate survival for patients with brain metastases. J Clin Oncol 2012;30:419-25.

8. American Cancer Society. Cancer Facts and Figures 2016. Atlanta, GA: American Cancer Society; 2016.

9. Sperduto PW, Yang TJ, Beal K, Pan H, Brown PD, et al. The effect of gene alterations and tyrosine kinase inhibition on survival and cause of death in patients with adenocarcinoma of the lung and brain metastases. Int J Radiat Oncol Biol Phys 2016;96:406-13.

10. Gaspar L, Scott C, Rotman M, Asbell S, Phillips T, et al Recursive partitioning analysis (RPA) of prognostic factors in three Radiation Therapy Oncology Group (RTOG) brain metastases trials. Int J Radiat Oncol Biol Phys 1997;37:745-51.

11. Sperduto PW, Chao ST, Sneed PK, Luo X, Suh J, et al. Diagnosis-specific prognostic factors, indexes, and treatment outcomes for patients with newly diagnosed brain metastases: a multi-institutional analysis of 4,259 patients. Int J Radiat Oncol Biol Phys 2010;77:655-61.

12. Sperduto PW, Yang TJ, Beal K, Pan H, Brown PD, et al. Estimating survival in patients with lung cancer and brain metastases: an update of the graded prognostic assessment for lung cancer using molecular markers (lung-molGPA). JAMA Oncol 2017;3:827-31.

13. Patchell RA, Tibbs PA, Walsh JW, Dempsey RJ, Maruyama Y, et al. A randomized trial of surgery in the treatment of single metastases to the brain. N Engl J Med 1990;322:494-500.

14. Weinberg JS, Lang FF, Sawaya R. Surgical management of brain metastases. Curr Oncol Rep 2001;3:476-83.

15. Al-Shamy G, Sawaya R. Management of brain metastases: the indispensable role of surgery. J Neurooncol 2009;92:275-82.

16. Kalkanis SN, Kondziolka D, Gaspar LE, Burri SH, Asher AL, et al. The role of surgical resection in the management of newly diagnosed brain metastases: a systematic review and evidence-based clinical practice guideline. J Neurooncol 2010;96:33-43.

17. Andrews DW, Scott CB, Sperduto PW, Flanders AE, Gaspar LE, et al. Whole brain radiation therapy with or without stereotactic radiosurgery boost for patients with one to three brain metastases: phase III results of the RTOG 9508 randomised trial. Lancet 2004;363:1665-72.

18. Patchell RA, Tibbs PA, Regine WF, Dempsey RJ, Mohiuddin M, et al. Postoperative radiotherapy in the treatment of single metastases to the brain: a randomized trial. JAMA 1998;280:1485-9.

19. Auchter RM, Lamond JP, Alexander E, Buatti JM, Chappell R, et al. A multiinstitutional outcome and prognostic factor analysis of radiosurgery for resectable single brain metastasis. Int J Radiat Oncol Biol Phys 1996;35:27-35.

20. Muacevic A, Kreth FW, Horstmann GA, Schmid-Elsaesser R, Wowra B, et al. Surgery and radiotherapy compared with gamma knife radiosurgery in the treatment of solitary cerebral metastases of small diameter. J Neurosurg 1999;91:35-43.

21. Muacevic A, Wowra B, Siefert A, Tonn JC, Steiger HJ, et al. Microsurgery plus whole brain irradiation versus Gamma Knife surgery alone for treatment of single metastases to the brain: a randomized controlled multicentre phase III trial. J Neurooncol 2008;87:299-307.

22. Churilla TM CI, Chowdury IH, Handorf E, Collette L, Collette S, et al. Comparison of local control of brain metastasis with stereotactic radiosurgery versus surgical resection: a secondary analysis of a randomized clinical trial. JAMA Oncol 2018; doi: 10.1001/ 
jamaoncol.2018.4610.

23. Kelly PJ, Lin YB, Yu AY, Alexander BM, Hacker F, et al. Stereotactic irradiation of the postoperative resection cavity for brain metastasis: a frameless linear accelerator-based case series and review of the technique. Int J Radiat Oncol Biol Phys 2012;82:95-101.

24. Soltys SG, Adler JR, Lipani JD, Jackson PS, Choi CY, et al. Stereotactic radiosurgery of the postoperative resection cavity for brain metastases. Int J Radiat Oncol Biol Phys 2008;70:187-93.

25. Brennan C, Yang TJ, Hilden P, Zhang Z, Chan K, et al. A phase 2 trial of stereotactic radiosurgery boost after surgical resection for brain metastases. Int J Radiat Oncol Biol Phys 2014;88:130-6.

26. Kępka L, Tyc-Szczepaniak D, Bujko K, Olszyna-Serementa M, Michalski W, et al. Stereotactic radiotherapy of the tumor bed compared to whole brain radiotherapy after surgery of single brain metastasis: results from a randomized trial. Radiother Oncol 2016;121:217-24.

27. Atalar B, Modlin LA, Choi CY, Adler JR, Gibbs IC, et al. Risk of leptomeningeal disease in patients treated with stereotactic radiosurgery targeting the postoperative resection cavity for brain metastases. Int J Radiat Oncol Biol Phys 2013;87:713-8.

28. Johnson MD, Avkshtol V, Baschnagel AM, Meyer K, Ye H, et al. Surgical resection of brain metastases and the risk of leptomeningeal recurrence in patients treated with stereotactic radiosurgery. Int J Radiat Oncol Biol Phys 2016;94:537-43.

29. Soliman H, Ruschin M, Angelov L, Brown PD, Chiang VLS, et al. Consensus contouring guidelines for postoperative completely resected cavity stereotactic radiosurgery for brain metastases. Int J Radiat Oncol Biol Phys 2018;100:436-42.

30. Patel KR, Burri SH, Boselli D, Symanowski JT, Asher AL, et al. Comparing pre-operative stereotactic radiosurgery (SRS) to post-operative whole brain radiation therapy (WBRT) for resectable brain metastases: a multi-institutional analysis. J Neurooncol 2017;131:611-8.

31. NRG Oncology. NRG Oncology Semiannual Meeting 2016. Available from: https://www.nrgoncology.org/LinkClick.aspx?fileticket=TTkE Mgz9_7U\%3D\&portalid=0. [Last accessed on 17 Jan 2019]

32. Sperduto PW, Shanley R, Luo X, Andrews D, Werner-Wasik M, et al. Secondary analysis of RTOG 9508, a phase 3 randomized trial of whole-brain radiation therapy versus WBRT plus stereotactic radiosurgery in patients with 1-3 brain metastases; poststratified by the graded prognostic assessment (GPA). Int J Radiat Oncol Biol Phys 2014;90:526-31.

33. Aoyama H, Shirato H, Tago M, Nakagawa K, Toyoda T, et al. Stereotactic radiosurgery plus whole-brain radiation therapy vs stereotactic radiosurgery alone for treatment of brain metastases: a randomized controlled trial. JAMA 2006;295:2483-91.

34. Chang EL, Wefel JS, Hess KR, Allen PK, Lang FF, et al. Neurocognition in patients with brain metastases treated with radiosurgery or radiosurgery plus whole-brain irradiation: a randomised controlled trial. Lancet Oncol 2009;10:1037-44.

35. Kocher M, Soffietti R, Abacioglu U, Villà S, Fauchon F, et al. Adjuvant whole-brain radiotherapy versus observation after radiosurgery or surgical resection of one to three cerebral metastases: results of the EORTC 22952-26001 study. J Clin Oncol 2011;29:134-41.

36. Tsao M, Xu W, Sahgal A. A meta-analysis evaluating stereotactic radiosurgery, whole-brain radiotherapy, or both for patients presenting with a limited number of brain metastases. Cancer 2012;118:2486-93.

37. Brown PD, Jaeckle K, Ballman KV, Farace E, Cerhan JH, et al. Effect of radiosurgery alone vs radiosurgery with whole brain radiation therapy on cognitive function in patients with 1 to 3 brain metastases: a randomized clinical trial. JAMA 2016;316:401-9.

38. Aoyama H, Tago M, Shirato H; Japanese Radiation Oncology Study Group 99-1 (JROSG 99-1) Investigators. Stereotactic radiosurgery with or without whole-brain radiotherapy for brain metastases: secondary analysis of the JROSG 99-1 randomized clinical trial. JAMA Oncol 2015;1:457-64.

39. Churilla TM, Handorf E, Collette S, Collette L, Dong Y, et al. Whole brain radiotherapy after stereotactic radiosurgery or surgical resection among patients with one to three brain metastases and favorable prognoses: a secondary analysis of EORTC 22952-26001. Ann Oncol 2017;28:2588-94.

40. Sahgal A, Aoyama H, Kocher M, Neupane B, Collette S, et al. Phase 3 trials of stereotactic radiosurgery with or without whole-brain radiation therapy for 1 to 4 brain metastases: individual patient data meta-analysis. Int J Radiat Oncol Biol Phys 2015;91:710-7.

41. Churilla TM, Ballman KV, Brown PD, Twohy EL, Jaeckle K, et al. Stereotactic radiosurgery with or without whole-brain radiation therapy for limited brain metastases: a secondary analysis of the North Central Cancer Treatment Group N0574 (Alliance) randomized controlled trial. Int J Radiat Oncol Biol Phys2017;99:1173-8.

42. Aoyama H, Tago M, Kato N, Toyoda T, Kenjyo M, et al. Neurocognitive function of patients with brain metastasis who received either whole brain radiotherapy plus stereotactic radiosurgery or radiosurgery alone. Int J Radiat Oncol Biol Phys 2007;68:1388-95.

43. Meyers CA, Wefel JS. The use of the mini-mental state examination to assess cognitive functioning in cancer trials: no ifs, ands, buts, or sensitivity. J Clin Oncol 2003;21:3557-8.

44. Soffietti R, Kocher M, Abacioglu UM, Villa S, Fauchon F, et al. A European Organisation for Research and Treatment of Cancer phase III trial of adjuvant whole-brain radiotherapy versus observation in patients with one to three brain metastases from solid tumors after surgical resection or radiosurgery: quality-of-life results. J Clin Oncol 2013;31:65-72.

45. ASTRO Update. Ten things physicians and patients should question. Available from: https://www.reproductivefacts.org/news-andpublications/choosing-wisely2/. [Last accessed on 24 Jan 2019]

46. Meyers CA, Smith JA, Bezjak A, Mehta MP, Liebmann J, et al. Neurocognitive function and progression in patients with brain metastases treated with whole-brain radiation and motexafin gadolinium: results of a randomized phase III trial. J Clin Oncol 2004;22:157-65.

47. Regine WF, Huhn JL, Patchell RA, St Clair WH, Strottmann J, et al. Risk of symptomatic brain tumor recurrence and neurologic deficit after radiosurgery alone in patients with newly diagnosed brain metastases: results and implications. Int J Radiat Oncol Biol Phys 2002;52:333-8.

48. Tsao MN, Rades D, Wirth A, Lo SS, Danielson BL, et al. Radiotherapeutic and surgical management for newly diagnosed brain metastasis(es): an American Society for Radiation Oncology evidence-based guideline. Pract Radiat Oncol 2012;2:210-25.

49. Mulvenna P, Nankivell M, Barton R, Faivre-Finn C, Wilson P, et al. Dexamethasone and supportive care with or without whole brain radiotherapy in treating patients with non-small cell lung cancer with brain metastases unsuitable for resection or stereotactic radiotherapy (QUARTZ): results from a phase 3, non-inferiority, randomised trial. Lancet 2016;388:2004-14.

50. Gondi V, Hermann BP, Mehta MP, Tomé WA. Hippocampal dosimetry predicts neurocognitive function impairment after fractionated stereotactic radiotherapy for benign or low-grade adult brain tumors. Int J Radiat Oncol Biol Phys 2013;85:348-54. 
51. Gondi V, Pugh SL, Tome WA, Caine C, Corn B, et al. Preservation of memory with conformal avoidance of the hippocampal neural stemcell compartment during whole-brain radiotherapy for brain metastases (RTOG 0933): a phase II multi-institutional trial. J Clin Oncol 2014;32:3810-6.

52. Oehlke O, Wucherpfennig D, Fels F, Frings L, Egger K, et al. Whole brain irradiation with hippocampal sparing and dose escalation on multiple brain metastases: local tumour control and survival. Strahlenther Onkol 2015;191:461-9.

53. Gondi V, Deshmukh S, Brown PD, Wefel JS, Tome WA, et al. Preservation of neurocognitive function with conformal avoidance of the hippocampus during whole-brain radiotherapy for brain metastases: preliminary results of phase III trial. Available from: https://www.astro. org/ASTRO/media/ASTRO/Meetings\%20and\%20Education/PDFs/BOA18/FullTextAbstracts.pdf. [Last accessed on 24 Jan 2019]

54. Brown PD, Pugh S, Laack NN, Wefel JS, Khuntia D, et al. Memantine for the prevention of cognitive dysfunction in patients receiving whole-brain radiotherapy: a randomized, double-blind, placebo-controlled trial. Neuro Oncol 2013;15:1429-37.

55. ClinicalTrials.gov. Memantine hydrochloride and whole-brain radiotherapy with or without hippocampal avoidance in reducing neurocognitive decline in patients with brain metastases. Available from: https://clinicaltrials.gov/ct2/show/NCT02360215?cond=Memantin e+Hippocampus\&rank=1. [Last accessed on 17 Jan 2019]

56. Yamamoto M, Serizawa T, Shuto T, Akabane A, Higuchi Y, et al. Stereotactic radiosurgery for patients with multiple brain metastases (JLGK0901): a multi-institutional prospective observational study. Lancet Oncol 2014;15:387-95.

57. Yamamoto M, Serizawa T, Higuchi Y, Sato Y, Kawagishi J, et al. A multi-institutional prospective observational study of stereotactic radiosurgery for patients with multiple brain metastases (JLGK0901 study update): irradiation-related complications and long-term maintenance of mini-mental state examination scores. Int J Radiat Oncol Biol Phys 2017;99:31-40.

58. ClinicalTrials.gov. Stereotactic radiosurgery compared with whole brain radiotherapy (WBRT) for 5-15 brain metastases. Available from: https://clinicaltrials.gov/ct2/show/NCT03550391. [Last accessed on 24 Jan 2019]

59. ClinicalTrials.gov. Whole brain radiation versus stereotactic radiation (SRS) in patients with 5-20 brain metastases: a phase III, randomized clinical trial. Available from: https://clinicaltrials.gov/ct2/show/NCT03075072?term=NCT03075072\&rank=1. [Last accessed on 17 Jan 2019]

60. Eaton BR, LaRiviere MJ, Kim S, Prabhu RS, Patel K, et al. Hypofractionated radiosurgery has a better safety profile than single fraction radiosurgery for large resected brain metastases. J Neurooncol 2015;123:103-11.

61. Loganadane G, Hendriks L, Le Péchoux C, Levy A. The current role of whole brain radiation therapy in non-small cell lung cancer patients. J Thorac Oncol 2017;12:1467-77.

62. Park SJ, Kim HT, Lee DH, Kim KP, Kim SW, et al. Efficacy of epidermal growth factor receptor tyrosine kinase inhibitors for brain metastasis in non-small cell lung cancer patients harboring either exon 19 or 21 mutation. Lung Cancer 2012;77:556-60.

63. Iuchi T, Shingyoji M, Sakaida T, Hatano K, Nagano O, et al. Phase II trial of gefitinib alone without radiation therapy for Japanese patients with brain metastases from EGFR-mutant lung adenocarcinoma. Lung Cancer 2013;82:282-7.

64. Wu YL, Zhou C, Cheng Y, Lu S, Chen GY, et al. Erlotinib as second-line treatment in patients with advanced non-small-cell lung cancer and asymptomatic brain metastases: a phase II study (CTONG-0803). Ann Oncol 2013;24:993-9.

65. Wen PY. Controversies in neuro-oncology: role of whole-brain radiation therapy in the treatment of newly diagnosed brain metastases. Neuro Oncol 2015;17:915.

66. Magnuson WJ, Lester-Coll NH, Wu AJ, Yang TJ, Lockney NA, et al. Management of brain metastases in tyrosine kinase inhibitornaive epidermal growth factor receptor-mutant non-small-cell lung cancer: a retrospective multi-institutional analysis. J Clin Oncol 2017;35:1070-7.

67. Costa DB, Shaw AT, Ou SH, Solomon BJ, Riely GJ, et al. Clinical experience with crizotinib in patients with advanced ALK-rearranged non-small-cell lung cancer and brain metastases. J Clin Oncol 2015;33:1881-8.

68. ASCO. Alectinib versus crizotinib in treatment-naive advanced ALK-positive non-small cell lung cancer (NSCLC): primary results of the global phase III ALEX study. Available from: http://ascopubs.org/doi/abs/10.1200/JCO.2017.35.18_suppl.LBA9008. [Last accessed on 24 Jan 2019]

69. Olmez I, Donahue BR, Butler JS, Huang Y, Rubin P, et al. Clinical outcomes in extracranial tumor sites and unusual toxicities with concurrent whole brain radiation (WBRT) and erlotinib treatment in patients with non-small cell lung cancer (NSCLC) with brain metastasis. Lung Cancer 2010;70:174-9.

70. Goldberg SB, Gettinger SN, Mahajan A, Chiang AC, Herbst RS, et al. Pembrolizumab for patients with melanoma or non-small-cell lung cancer and untreated brain metastases: early analysis of a non-randomised, open-label, phase 2 trial. Lancet Oncol 2016;17:976-83.

71. Kanai O, Fujita K, Okamura M, Nakatani K, Mio T. Severe exacerbation or manifestation of primary disease related to nivolumab in nonsmall-cell lung cancer patients with poor performance status or brain metastases. Ann Oncol 2016;27:1354-6.

72. Chen L, Douglass J, Kleinberg L, Ye X, Marciscano AE, et al. Concurrent immune checkpoint inhibitors and stereotactic radiosurgery for brain metastases in non-small cell lung Cancer, melanoma, and renal cell carcinoma. Int J Radiat Oncol Biol Phys 2018;100:916-25.

73. Hubbeling HG, Schapira EF, Horick NK, Goodwin KEH, Lin JJ, et al. Safety of combined PD-1 pathway inhibition and intracranial radiation therapy in non-small cell lung cancer. J Thorac Oncol 2018;13:550-8. 